\title{
The effects of foam rolling of plantar fascia on the arches of the foot and flexibility
}

\author{
A - preparing concepts \\ $\mathrm{B}$ - formulating methods \\ $\mathrm{C}$ - conducting research \\ $\mathrm{D}$ - processing results \\ E - interpretation and \\ conclusions \\ F - editing the \\ Jakub Olewiński ${ }^{A-F}$, Artur Jagodziński $i^{A-C}$, Katarzyna Bienias ${ }^{A, E-F}$, \\ Izabela Rutkowska ${ }^{\mathrm{E}-\mathrm{F}}$, Joanna Ścibek ${ }^{\mathrm{A}-\mathrm{F}}$ \\ Faculty of Rehabilitation, Józef Piłsudski University of Physical Education \\ in Warsaw
} final version

https://doi.org/10.5114/areh.2019.84186

Key words: flexibility, self-myofascial release, longitudinal foot arching

\section{Introduction}

Fascial tension can be estimated using functional tests. For example, the trunk forward bend range of motion is closely related to the state of tension of the superficial back line (SBL). SBL is a myofascial structure which connects and protects the entire posterior surface of the body. An increased tension of the SBL-forming structures reduces the range of the trunk forward bend $[1,2]$ The hamstring strain injury is one of the musculoskeletal impairments associated with SBL. Although the literature remains inconsistent in this area, poor muscle flexibility is suggested as a risk factor of a muscle strain injury [3]. It is noteworthy that improving the hamstring flexibility is possible also by a remote myofascial release. Influencing the remote parts of SBL (plantar fascia and suboccipital region) turned out to be an effective way of improving the results in the knee extension angle test [4]. The SBL-forming structures linkages are described by several investigators. Hyong and Kang [5] indicate that hamstring static stretching improves the cervical spine range of motion. Hyong and Kim [6] found that the greater 
values of cranial vertical angle were associated with the increased ankle plantar flexion range of motion. This means that a forward head posture results in limiting the normal ankle plantarflexion range of motion by the backward pull of the muscles by the fascia. Wilke et al. [7] conducted a study which revealed a positive influence of gastrocnemius and hamstring static stretching on the cervical spine range of motion. The structures located in the distal part of the SBL (foot) are directly related to the medial longitudinal arch of the foot. The shape of this arch is maintained thanks mainly to the plantar fascia, the tibialis posterior and peroneus longus and the planar intrinsic foot muscles [8,9]. Plantar fascia stiffens longitudinal arches of the foot during walking, reducing the effect of longitudinal arch flattening [10]. Although certain level of plantar fascia tension is necessary for resisting forces lowering the medial arch, excessive contracture of this structure is associated with developing higharched foot [11,12]. Taking it into account, in the high-arched population the myofascial release of the plantar side of the foot might be beneficial. One of the pathologies affecting plantar fascia is plantar fasciitis. It is associated with degenerative changes of the plantar fascia from noninflammatory causes. Myofascial tension might be included in the pathomechanism of this condition. Restoring the proper length and health of the connective tissue is believed to lead to a relief of the pressure on the pain sensitive structures such as nerves or blood vessels. Therefore, myofascial release is one of the conservative management methods of plantar fasciitis, presenting clinical effectiveness [13,14]. The most common clinical methods for myofascial release are manual therapy including osteopathic soft-tissue techniques, Rolfing - structural integration, muscle energy techniques or massage $[15,16]$. Regardless of the choice of clinical treatment a home program must be included to facilitate the desired, permanent tissue changes and enable a successful outcome. A classic form of selftherapy that can easily be performed by a patient at home is called self-myofascial release (SMR) and uses a foam roller. Foam rolling is a widely used form of fascia therapy in physical therapy [17]. This method uses dense foam rollers of various sizes [18]. Myofascial release with a foam roller allows for stimulation of tissue similar to that which occurs during manual therapy [19]. The purpose of SMR is to reduce the thickness, adhesion and tension of the connective and muscular tissue. During SMR with a foam roller, all tissues innervated by the mechanoand chemoreceptors are subjected to mechanical stress. This type of therapy is used to achieve several goals. It is supposed to improve fascial remodeling, increase its elasticity and health, improve hydration and improve proprioception $[17,18]$. The purpose of the experiment was to determine the acute and chronic effect of the SMR of the plantar fascia on the arches of the foot and on the range of the trunk forward bend.

\section{Material and methods}

\section{The course of the experiment}

Each participant underwent three series of measurements carried out at the Central Research Laboratory of the Józef Piłsudski University of Physical Education in Warsaw. In each series the following measurements were taken: the Thomayer's test, the podoscopic examination (Clarke's angle), and the measurement of the height of the navicular bone. Subjects did not perform any warm-up before the measurements. Each participant signed a consent form. The Ethics Committee of the University of Physical Education in Warsaw gave permission to conduct the study.

\section{Participants}

The inclusion criteria: 18-25 years of age, no professional sports training. The exclusion criteria: surgical orthopedic surgery that may have influenced the stability or the range of motion in the examined joints, recent musculoskeletal trauma that might affect the results, joint hypermobility assessed on the Beighton scale [20]. Candidates who scored 5 points or more were excluded from the study. 48 potential participants were screened for the inclusion criteria. 6 were excluded due to generalized joint laxity, 5 due to a recent musculoskeletal trauma, 7 were lost to follow-up by being unreachable. Eventually, the participants of this experiment were 30 healthy students from two Warsaw Universities.

The participants were randomly divided into a control group $(\mathrm{n}=15)$ and an experimental group $(n=15)$. In the control group, 8 participants were women and $7 \mathrm{men}$. In the experimental group there were 7 women and 8 men (Table 1). 
Tab. 1. Demographic data of subjects

\begin{tabular}{|l|c|c|}
\hline & $\begin{array}{c}\text { Experimental group } \\
(\mathrm{n}=15)\end{array}$ & Control group $(\mathrm{n}=15)$ \\
\cline { 2 - 3 } & $\begin{array}{c}\text { Mean } \pm \text { SD and } \\
\text { MIN MAX volumes }\end{array}$ & $\begin{array}{c}\text { Mean } \pm \text { SD and } \\
\text { MIN MAX volumes }\end{array}$ \\
\hline Age [years] & $21 \pm 1,70(19 \div 25)$ & $21,67 \pm 1,70(19 \div 24)$ \\
\hline Height [cm] & $175 \pm 12,46(157 \div 204)$ & $176 \pm 10,27(159 \div 192)$ \\
\hline Weight $[\mathrm{kg}]$ & $68 \pm 13,46(51 \div 96)$ & $67 \pm 10,88(52 \div 85)$ \\
\hline $\begin{array}{l}\text { Beighton scale } \\
\text { [p] }\end{array}$ & $2 \pm 1,22(0 \div 4)$ & $1,47 \pm 1,15(0 \div 4)$ \\
\hline
\end{tabular}

\section{Measurement methods}

Three measurements of the examined features were performed using the following methods:

The Thomayer's test (fingers-to-floor test) involved making the maximum forward bend with feet together and straight knee joints while standing on the platform, followed by measuring the distance between the fingertip III and the point placed $40 \mathrm{~cm}$ beneath the platform. This allowed to obtain absolute values. Prior to the measurement, the subjects performed three forward bends in the full range of motion. The fourth attempt was measured. This test has excellent validity, reliability, and responsiveness [21].

The height of the navicular bone was measured using a vernier caliper, each time at the same foot setting on the platform which is a part of the Biodex System SD. The feet were positioned in the same place using a system of letters and numbers written on the surface of the platform. Palpation of the most medial prominence of the navicular tuberosity was performed. The resulting measurement was the distance between the palpated structure and the platform.

The examination with the podoscope was performed using the Posmed podoscope with the ElPodo version 1.8 software. After taking a photo with the podoscope, the Clarke's angle was calculated [22]. Clarke's angle is a highly accurate tool in predicting flat foot, with sensibility at the level of $89.8 \%$ [23].

A team of 3 trained physiotherapists was involved in conducting the measurements and each person was responsible for performing one type of measurement.

\section{Intervention}

The roller "Trigger Point Nano" was used for the self-myofascial release of the plantar aponeurosis.
The subjects from the experimental group (EG) performed bilateral foam rolling with stress causing discomfort estimated at 6-7 on the Numeric Rating Scale (NRS). 10 slow rolling repetitions were performed on each side in a standing position. One repetition was rolling from the level of the metatarsal bone head to the heel and back. Very slow pace of the intervention was required. One repetition was supposed to last approximately 10 seconds. Between measurement I and II the subjects from the EG performed a foam rolling sequence so that the immediate effect could be assessed. Measurement I was taken right before, and measurement II was taken right after the intervention. Between measurement II and III the participants from the EG performed intervention every day for two weeks at the same time of day. The subjects from the CG did not perform any intervention.

\section{Statistical analysis}

Statistical analysis was performed using the Statistica 12.1 program. The analysis of ANOVA variance for repeated measures was used to examine the differences in the values of the examined features between the groups. The independent samples t-Test was used to determine the between group differences at the baseline. Significance was defined as corresponding to the test probability of $p<0.05$.

\section{Results}

\section{Thomayer's test}

The results of the Thomayer's test are illustrated in Table 2. At the baseline, there were no differences between the groups in the Thomayer's test results $(p=0.59)$. Changes in the Thomayer's test results caused by the intervention did not show a statistically significant difference between the EG and $\mathrm{CG}\left(\mathrm{F}_{2,56}=0.576, \mathrm{p}=0.5654, \eta^{2}=0.0202\right)$.

\section{Clarke's angle}

The Clarke's angle values are shown in Table 3. At the baseline, there were no differences between the groups in the Clarke's angle values for the right foot $(p=0.29)$ and for the left foot $(p=0.33)$. Changes in the Clarke's angle values caused by the intervention did not show a statistically significant difference between the EG and CG for the right foot $\left(\mathrm{F}_{2,56}=1.547, \mathrm{p}=0.2219, \eta^{2}=0.0524\right)$ and for the left foot $\left(\mathrm{F}_{2,56}=1.501, \mathrm{p}=0.2317, \eta^{2}=0.0509\right)$. 


\section{Height of the navicular bone}

Values for the height of the navicular bone are shown in Table 4. The value of the navicular bone height showed a statistically significant difference between the groups in the first measurement for the right foot $(p=0.0022)$ and for the left $(p=0.0155)$. Changes in the navicular bone height caused by the intervention did not show a statistically significant difference between the EG and CG for the right foot $\left(\mathrm{F}_{2,56}=1.469, \mathrm{p}=0.2388, \eta^{2}=0.0499\right)$ and for the left foot $\left(F_{2,56}=1.539, \mathrm{p}=0.2234, \eta^{2}=0.0521\right)$.

Tab. 2. Thomayer's test results. The value is the distance between the fingertip III from the point placed $40 \mathrm{~cm}$ beneath the platform. No interaction effect was found ( $p>0.05)$

\begin{tabular}{|l|c|c|}
\hline & $\begin{array}{c}\text { Experimental group } \\
(\mathrm{n}=15)\end{array}$ & Control group $(\mathrm{n}=15)$ \\
\cline { 2 - 3 } & $\begin{array}{c}\text { Mean } \pm \text { SD and MIN } \\
\text { MAX volumes }\end{array}$ & $\begin{array}{c}\text { Mean } \pm \text { SD and MIN } \\
\text { MAX volumes }\end{array}$ \\
\hline Thomayer $1[\mathrm{~cm}]$ & $36 \pm 14,14(9 \div 57)$ & $38 \pm 10,61(27 \div 65)$ \\
\hline Thomayer 2 $[\mathrm{cm}]$ & $34 \pm 13,56(8 \div 56)$ & $37 \pm 10,45(25 \div 64)$ \\
\hline Thomayer 3 $[\mathrm{cm}]$ & $33 \pm 12,93(12 \div 59)$ & $36 \pm 9,09(25 \div 57)$ \\
\hline
\end{tabular}

Thomayer $=$ Thomayer's test, $(1=$ pre-test, $2=$ acute effect, $3=$ chronic effect)

Tab. 3. Clarke's angle. No interaction effect was found $(\mathrm{p}>0.05)$

\begin{tabular}{|c|c|c|}
\hline & Experimental group $(\mathrm{n}=15)$ & Control group $(\mathrm{n}=15)$ \\
\hline & $\begin{array}{c}\text { Mean } \pm \text { SD and MIN MAX } \\
\text { volumes }\end{array}$ & $\begin{array}{c}\text { Mean } \pm \text { SD and MIN MAX } \\
\text { volumes }\end{array}$ \\
\hline $\mathrm{CA} 1 \mathrm{R}\left[{ }^{\circ}\right]$ & $48,1 \pm 4,98(39 \div 55,7)$ & $45,1 \pm 8,10(31,5 \div 60)$ \\
\hline $\mathrm{CA} 2 \mathrm{R}\left[{ }^{\circ}\right]$ & $48,0 \pm 5,23(37,7 \div 55,4)$ & $44,8 \pm 8,18(28,9 \div 57,9)$ \\
\hline $\mathrm{CA} 3 \mathrm{R}\left[{ }^{\circ}\right]$ & $47,1 \pm 7,32(37,2 \div 59,9)$ & $41,7 \pm 6,64(28,6 \div 50,8)$ \\
\hline CA1L $\left[{ }^{\circ}\right]$ & $46,4 \pm 5,22(40,3 \div 56,0)$ & $43,8 \pm 8,29(28,8 \div 59,1)$ \\
\hline $\mathrm{CA} 2 \mathrm{~L}\left[{ }^{\circ}\right]$ & $45,1 \pm 4,00(37,8 \div 52,6)$ & $41,5 \pm 6,84(27,9 \div 52,5)$ \\
\hline $\mathrm{CA} 3 \mathrm{~L}\left[{ }^{\circ}\right]$ & $46,2 \pm 5,44(39,9 \div 55,1)$ & $41,0 \pm 8,61(22,8 \div 54,7)$ \\
\hline
\end{tabular}

$\mathrm{CA}=$ Clarke's angle; $(1=$ pre-test, 2 = acute effect, $3=$ chronic effect $)$ $\mathrm{R}=$ measurement of right foot, $\mathrm{L}=$ measurement of left foot

Tab. 4. Navicular bone height. No interaction effect was found $(\mathrm{p}>0.05)$

\begin{tabular}{|l|c|c|}
\hline & $\begin{array}{c}\text { Experimental group } \\
(\mathrm{n}=15)\end{array}$ & $\begin{array}{c}\text { Control group } \\
(\mathrm{n}=15)\end{array}$ \\
\cline { 2 - 3 } & $\begin{array}{c}\text { Mean } \pm \text { SD and } \\
\text { MIN MAX volumes }\end{array}$ & $\begin{array}{c}\text { Mean } \pm \text { SD and } \\
\text { MIN MAX volumes }\end{array}$ \\
\hline NB1R $[\mathrm{mm}]$ & $39 \pm 5,57(27 \div 50)$ & $31 \pm 5,93(22 \div 41)$ \\
\hline NB2R $[\mathrm{mm}]$ & $37 \pm 5,65(30 \div 53)$ & $32 \pm 6,28(18 \div 40)$ \\
\hline NB3R $[\mathrm{mm}]$ & $38 \pm 4,88(33 \div 51)$ & $33 \pm 5,55(21 \div 40)$ \\
\hline NB1L $[\mathrm{mm}]$ & $36 \pm 4,35(28 \div 46)$ & $31 \pm 7,08(22 \div 42)$ \\
\hline NB2L $[\mathrm{mm}]$ & $35 \pm 5,01(28 \div 47)$ & $32 \pm 6,87(23 \div 43)$ \\
\hline NB3L $[\mathrm{mm}]$ & $36 \pm 4,27(29 \div 46)$ & $31 \pm 5,91(22 \div 41)$ \\
\hline
\end{tabular}

$\mathrm{NB}=$ navicular bone height $(1=$ pre-test, $2=$ acute effect, $3=$ chronic effect)

$\mathrm{R}=$ measurement of right foot, $\mathrm{L}=$ measurement of left foot

\section{Discussion}

Research on SMR has been constantly evolving in recent years. The influence of SMR is assumed to enhance, among others, the tissue excursion [24]. The aim of the study was to determine the effect of loosening tissues located on the plantar side of the foot on its longitudinal arching and on the range of the trunk forward bend. The acute effect of plantar aponeurosis foam rolling on the range of motion in finger-to-floor test is clearly visible in clinical practice, which led the authors of this study to investigate it on a larger group in laboratory conditions. This conjecture was also based upon reports from literature. Griev et al. [25] studied the effect of the myofascial release of the plantar part of the foot with a tennis ball on the result of the sit-andreach test. Subjects from the experimental group performed an intervention for 2 minutes on each foot, applying force that caused clear discomfort. The range of motion in the experimental group increased significantly and showed a statistically significant difference in comparison to the control group. This effect could be associated with the fact that the plantar fascia and the short finger flexors belong to the superficial back line. The tested motor pattern loads and connects all tracks and stations of the fascial line. It is assumed that working only in one area of this line can have a beneficial effect on the state of its tension [2]. Despite this assumption, in this study, local loosening of soft tissues located on the plantar side of the foot turned out to have no effect on the range of the global motor pattern, which is the forward bend performed with straight knee joints. There are various variables that might be responsible for this lack of effect. The first one is the duration of the intervention. There is no consensus on how long the foam-rolling sequence should last. In the literature the duration ranges from $60 \mathrm{sec}$. to $180 \mathrm{sec}$., performed in one set or divided into two sets [26-29]. The most effective pressure also remains unknown. There were studies in which the pressure was not controlled [29] or was set at the level of 8 on the pain level scale [28]. The foam-rolling protocol used in this study (10 repetitions, discomfort estimated at 6-7 on the NRS) turned out to be not effective. No differences were observed between the groups in the Clarke's angle value. The lack of effect might also be associated with the inclusion criteria, which aimed at healthy 
subjects who presented no significant abnormalities in foot structure. The average Clarke's angle value was in the norm at the baseline. Despite the fact that the height of the navicular bone was significantly different between the groups in the first measurement, the following calculations showed no effect of the intervention on this feature. The baseline difference makes the authors treat the results of this measurement with special caution. Determining the impact of this intervention on changing the height of the arches of the foot requires further research. Obtaining the effect of relaxation after foam-rolling could be related to the phenomenon of hydration of the connective tissue under the influence of mechanical pressure. Two-thirds of the volume of the fascial tissue is water, which is squeezed out of the zones subjected to pressure. When the application of external force ends, the tissues are filled with new liquid coming from the tissues surrounding the treated area [30]. Perhaps in order to obtain a more significant effect, an even slower pace of intervention could be considered, for example by strictly controlling the time taken to perform one repetition of foam-rolling. A very slow pace can more effectively use the phenomenon of thixotropy. It is related to the properties of colloidal substances which form connective tissue. It involves switching from a thick gel state to a more liquid sol. This phenomenon occurs under the influence of thermal energy or mechanical pressure [31].

\section{Limitations}

The small size of the sample and its selection from the student population does not allow for general conclusions to be drawn from the obtained results. The small sample size also increases the chance of occurrence of the type II error. The use of Clarke's angle to assess the longitudinal arch of the foot requires a lot of experience in editing podoscopic pictures and is associated with the possibility of making a mistake when applying points to the contour of the plantar part of the foot. The fingers-floor test can only show an increase in movement in the global pattern. However, it does indicate in which area of the body the range of motion has changed. The result may also depend on such factors as the physical activity of the subject the day before or mental tension during testing.

\section{Conclusions}

Self-myofascial release of the plantar fascia with the use of a foam-roller does not affect the medial longitudinal arch of the foot evaluated by the Clarke's angle and the navicular bone height. This type of intervention showed no influence on the trunk forward bend range of motion. Further research is needed on the influence of SMR by means of a foam-roller on various biomechanical and physiological parameters of the human body.

\section{References}

1. Myers TW. The 'anatomy trains'. J Bodyw Mov Ther. 1997 Jan;1(2):91-101.

2. Myers TW. Anatomy Trains: Myofascial Meridians for Manual and Movement Therapists, third ed. United States of America: Churchill Livingstone Elsevier; 2014.

3. Liu H, Garrett W, Moorman C, Yu B. Injury rate, mechanism, and risk factors of hamstring strain injuries in sports: A review of the literature. J Sport Health Sci. 2012 Sep;1(2):92-101.

4. Joshi DG, Balthillaya G, Prabhu A. Effect of remote myofascial release on hamstring flexibility in asymptomatic individuals - A randomized clinical trial. J Bodyw Mov Ther. 2018 Jul;22(3):832-7.

5. Hyong IH, Kang JH. The immediate effects of passive hamstring stretching exercises on the cervical spine range of motion and balance. J Phys Ther Sci. 2013;25(1):113-6.

6. Hyong IH, Kim JH. The Effect of Forward Head on Ankle Joint Range of Motion and Static Balance. J Phys Ther Sci. 2012;(24):925-27.

7. Wilke J, Vogt L, Niederer D, Banzer W. Is remote stretching based on myofascial chains as effective as local exercise? A randomised-controlled trial. J Sports Sci. 2017 Oct;35(20):2021-7.

8. Okamura K, Kanai S, Hasegawa M, Otsuka A, Oki S. The effect of additional activation of the plantar intrinsic foot muscles on foot dynamics during gait. Foot (Edinb). 2018 Mar;34:1-5.

9. Łukasik E, Kapiński N, Mioduszewski A, Wychowański M, Wit A. Effects of subtalar joint hypermobility on load-bearing capability of the musculoskeletal system of the foot during free gait- literature review. Adv Rehab. 2018;(3):37-44.

10. Guo J, Liu X, Ding X, Wang L, Fan Y. Biomechanical and mechanical behavior of the plantar fascia in macro and micro structures. J Biomech. 2018 Jul;76:160-6. 
11. Angin S, Mickle KJ, Nester CJ. Contributions of foot muscles and plantar fascia morphology to foot posture. Gait Posture. 2018 Mar;61:238-42.

12. Woźniacka R, Bac A, Matusik S, Szczygieł E, Ciszek E. Body weight and the medial longitudinal foot arch: high-arched foot, a hidden problem? Eur J Pediatr. 2013 May;172(5):683-91.

13. Ajimsha MS, Binsu D, Chithra S. Effectiveness of myofascial release in the management of plantar heel pain: a randomized controlled trial. Foot (Edinb). 2014 Jun;24(2):66-71.

14. Kage V, Bindra R. Effect of active release technique $\mathrm{v} / \mathrm{s}$ myofascial release on subjects with plantar fasciitis: a randomized clinical trial. Physiotherapy. 2015 May;(101):702.

15. Simmonds N, Miller P, Gemmell H. A theoretical framework for the role of fascia in manual therapy. J Bodyw Mov Ther. 2012 Jan;16(1):83-93.

16. Łukasik E, Targosiński P, Szymański M, Letkiewicz-Ryłów O, Styczeń P, Wychowański M. Comparing the effectiveness of myofascial techniques with massage in persons with upper crossed syndrome (preliminary report). Adv Rehab. 2017;(2):53-67.

17. Freiwald J, Baumgart C, Kühnemann M, Hoppe MW. Foam-Rolling in sport and therapy - Potential benefits and risks: Part 2 - Positive and adverse effects on athletic performance. Sports Orthop Traumatol. 2016 Sep;32(3):267-75.

18. Freiwald J, Baumgart C, Kühnemann M, Hoppe MW. Foam-Rolling in sport and therapy - Part 1 - Definitions, anatomy, physiology, and biomechanics. Sports Orthop Traumatol. 2016 Sep;32(3):258-66.

19. Couture G, Karlik D, Glass SC, Hatzel BM. The Effect of Foam Rolling Duration on Hamstring Range of Motion. Open Orthop J. 2015 Oct 2;9:450-5.

20. Boyle KL, Witt P, Riegger-Krugh C. Intrarater and Interrater Reliability of the Beighton and Horan Joint Mobility Index. J Athl Train. 2003 Dec;38(4):281-5.

21. Perret C, Poiraudeau S, Fermanian J, Colau MM, Benhamou MA, Revel M. Validity, reliability, and responsiveness of the fingertip-to-floor test. Arch Phys Med Rehabil. 2001 Nov;82(11):1566-70.

22. Głowacka-Mrotek I, Sowa M, Nowikiewicz T, Siedlecki Z, Hagner W, Zegarski W. Foot posture in female patients 5 years after breast-conserving surgery: a case-control study. Breast Cancer. 2018 May;25(3):325-33.

23. Pita-Fernández S, González-Martín C, Seoane-Pillado T, López-Calviño B, Pértega-Díaz S, Gil-Guillén V. Validity of footprint analysis to determine flatfoot using clinical diagnosis as the gold standard in a random sample aged 40 years and older. J Epidemiol. 2015;25(2):148-54.

24. Fleckenstein J, Wilke J, Vogt L, Banzer W. Preventive and Regenerative Foam Rolling are Equally Effective in Reducing Fatigue-Related Impairments of Muscle Function following Exercise. J Sports Sci Med. 2017 Dec 1;16(4):474-9.

25. Grieve R, Goodwin F, Alfaki M, Bourton AJ, Jeffries C, Scott H. The immediate effect of bilateral self myofascial release on the plantar surface of the feet on hamstring and lumbar spine flexibility: A pilot randomised controlled trial. J Bodyw Mov Ther. 2015 Jul;19(3):544-52.

26. Markovic G. Acute effects of instrument assisted soft tissue mobilization vs. foam rolling on knee and hip range of motion in soccer players. J Bodyw Mov Ther. 2015 Oct;19(4):690-6.

27. MacDonald GZ, Penney MD, Mullaley ME, Cuconato AL, Drake CD, Behm DG, et al. An acute bout of self-myofascial release increases range of motion without a subsequent decrease in muscle activation or force. J Strength Cond Res. 2013 Mar;27(3):812-21.

28. Monteiro ER, da Silva Novaes J, Cavanaugh MT, Hoogenboom BJ, Steele J, Vingren JL. et al. Quadriceps foam rolling and rolling massage increases hip flexion and extension passive range-of-motion. J Bodyw Mov Ther. 2019 Jan; ISSN 1360-8592

29. Mohr AR, Long BC, Goad CL. Effect of foam rolling and static stretching on passive hip-flexion range of motion. J Sport Rehabil. 2014 Nov;23(4):296-9.

30. Schleip R, Müller DG. Training principles for fascial connective tissues: scientific foundation and suggested practical applications. J Bodyw Mov Ther. 2013 Jan;17(1):103-15.

31. Schleip R. Fascial plasticity-a new neurobiological explanation: Part 1. J Bodyw Mov Ther. 2013 Jan;7(1):11-19 